\title{
A comprehensive seismic velocity model for the Netherlands based on lithostratigraphic layers
}

\section{W. van Dalfsen ${ }^{\star}$, J.C. Doornenbal, S. Dortland \& J.L. Gunnink}

TN0 Built Environment and Geosciences - Geological Survey of the Netherlands, P.0. Box 80015, 3508 TA Utrecht, the Netherlands.

* Corresponding author. Email: wim.vandalfsen@tno.nl

Manuscript received: September 2006; accepted November 2006

\begin{abstract}
A seismic velocity model is necessary to map depth and thickness of subsurface layers interpreted from seismic reflection images. We have built a seismic velocity model (VELMOD-1) for the entire Netherlands area, both onshore and offshore, using non-confidential data (sonic logs, time-depth pairs, lithostratigraphic marker depths and downhole position data) of 720 boreholes in DIN0 - National Geoscientific Portal, and a preliminary isochore map (in seismic traveltime representation) of the layer of the Zechstein Group. The model is based on the $V_{\text {int }}{ }^{-} z_{\text {mid }}$ method applied to the following lithostratigraphic layers: Lower, Middle and Upper North Sea groups; Chalk Group; Rijnland Group; Schieland, Scruff and Niedersachsen groups; Altena Group; Lower and Upper Germanic Trias groups; Upper Rotliegend Group; and Limburg Group. Per layer, the linear least squares approximation, applied to $\mathrm{V}_{\text {int }}$ as a function of $z_{\text {mid }}$, provides parameters $\mathrm{V}_{0}$ and $\mathrm{K}$ for a linear velocity function $\mathrm{V}(\mathrm{z})=\mathrm{V}_{0}+\mathrm{K} \cdot \mathrm{z}$. In $\mathrm{VELMOD}-1$, $\mathrm{K}$ is constant, at least at the scale of structural elements, whereas $\mathrm{V}_{0}$ varies with location. At borehole locations, $\mathrm{V}_{0}$ is calibrated such that traveltime through the layer according to the linear velocity model equals the traveltime according to the borehole data. A kriging procedure is applied to the calibrated $\mathrm{V}_{0}(\mathrm{x}, \mathrm{y})$-values resulting in an estimated $\mathrm{V}_{0}$-value at any other location. The model $\mathrm{V}_{0}$-values were determined on an areal grid with cells of $1 \mathrm{~km} \times 1 \mathrm{~km}$. On the same grid, kriged interval velocities constitute the model for the Zechstein Group. These interval velocities stem directly from interval velocities at borehole locations; at other positions they are also dependent on the thickness (in terms of seismic traveltime isochores) of the layer of the Zechstein Group. Maps are presented of the distributions of both $\mathrm{V}_{0}$ and its standard deviation for two layers: that of the Chalk Group and that of the Lower and Upper Germanic Trias groups.
\end{abstract}

Keywords: Netherlands, geostatistics, interval velocities, lithostratigraphic layers, seismic velocities, sonic logs

\section{Introduction}

TNO and exploration and production (E\&P) companies in the Netherlands have launched a Joint Industry Project, called VELMOD. In this project, a seismic velocity model (VELMOD-1) was built, based on non-confidential sonic, lithostratigraphic, seismic and borehole deviation data (per 01-01-2006) in DIN0 - National Geoscientific Portal. VELMOD-1 covers the whole Netherlands area, both onshore and offshore. Its parameters, on an areal grid with cells of $1 \mathrm{~km} \times 1 \mathrm{~km}$, will be accessible to the public as of March 1, 2008 (www.nlog.nl). First use of the model has been time-depth conversion of seismic horizons interpreted in regional mapping projects (Duin et al., 2006).
Interpretation of time domain seismic reflection data results in one or more seismic horizons. Each seismic horizon marks, in the time domain, a surface separating layers with different acoustic impedances. If the acoustically different layers can be associated with well defined lithostratigraphic layers, then a depth representation of a subsurface structure can be obtained through time-depth conversion using an appropriate velocity model.

For most lithostratigraphic layers, a convenient velocity model is of the type:

$$
v(x, y, z)=v_{0}(x, y)+k(x, y) \cdot z
$$


$\mathrm{v}(\mathrm{x}, \mathrm{y}, \mathrm{z})$ is seismic wave velocity at location $(\mathrm{x}, \mathrm{y})$ and depth $\mathrm{z}$, constrained by $z_{t}<z<z_{b}$ with $z_{t}$ and $z_{b}$ depth to top, respectively base of the lithostratigraphic layer. Ideally, the parameters $\mathrm{v}_{0}(\mathrm{x}, \mathrm{y})$ and $\mathrm{k}(\mathrm{x}, \mathrm{y})$ define that line segment, that presents the optimum linear approximation to the graph of true compressional wave velocity against depth through the lithostratigraphic layer. These parameters can be evaluated at boreholes with a sonic log, preferably digital and calibrated.

In practice, however, it is customary to take another approach. Instead of choosing $\mathrm{v}_{0}$ and $\mathrm{k}$ in a optimum linear approximation as stated above, the evaluation of model parameters is often based on the variation of interval velocities $\left(V_{\text {int }}\right)$ with mid-depths $\left(z_{\text {mid }}\right)$ at boreholes (Robein, 2003). In this $V_{\text {int }}-z_{\text {mid }}$ method there holds:

$$
\begin{aligned}
& \mathrm{V}_{\text {int }}=\left(\mathrm{z}_{\mathrm{b}}-\mathrm{z}_{\mathrm{t}}\right) / \Delta \mathrm{T} \text {, with } \Delta \mathrm{T} \text { vertical traveltime, and } \\
& \mathrm{z}_{\text {mid }}=\left(\mathrm{z}_{\mathrm{t}}+\mathrm{z}_{\mathrm{b}}\right) / 2
\end{aligned}
$$

The linear least squares fit trendline through the available pairs of $V_{\text {int }}$ and $z_{\text {mid }}$ results in parameters $V_{0}$ and $K$ that are inserted in the following linear velocity model:

$$
\mathrm{V}(\mathrm{z})=\mathrm{V}_{0}+\mathrm{K} \cdot \mathrm{z}
$$

This laterally uniform velocity model (both $\mathrm{V}_{0}$ and $\mathrm{K}$ independent of location coordinates $\mathrm{x}$ and $\mathrm{y}$ ) may produce acceptable time-to-depth conversion results in regions with likewise uniform lithostratification and geologic structure. The values of the parameters $V_{0}$ and $K$ are not necessarily equal to those of the parameters $v_{0}(x, y)$ and $k(x, y)$. The latter parameters define linearly depth-dependent velocities that are rather faithful to the true compressional wave velocities at a borehole, and result in the same traveltime $\Delta \mathrm{T}$ across a layer as the measured sonic velocities. On the other hand, $\mathrm{V}_{0}$ and $\mathrm{K}$ only need to result, at borehole locations, in traveltimes that are (nearly) equal to the measured traveltimes. In fact, $V_{0}$ and $\mathrm{K}$ are convenient ad-hoc parameters, in which are lumped together the effects of several factors that determine the compressional wave velocity of rock material of a lithostratigraphic layer. Among these factors are type and stratification of sediments, pore fluid regime, maximum burial depth, uplift and exhumation (Japsen, 2000).

Seismic velocity models with regionally location independent parameters $V_{0}$ and $\mathrm{K}$ have been used by TNO for its regional onshore studies. Geological maps have been published in the period 1991 - 2004 at scale 1 : 250000 . The onshore seismic velocity models, used until 2005, are specified in the Geological Atlas of the Subsurface of the Netherlands - onshore (TNO-NITG, 2004).

Meanwhile from 2000 onwards, velocity modelling was extended to the Netherlands offshore area. For six lithostratigraphic layers above the layer of the Zechstein Group, interval velocities from sonic logs of some 630 boreholes were grouped in clusters, and to each cluster was assigned a velocity model of the type $\mathrm{V}(\mathrm{z})=\mathrm{V}_{0}+\mathrm{K} \cdot \mathrm{z}$ (Doornenbal, 2001). This velocity model, however, is not attractive for the following reasons. One drawback is that the cluster boundaries do not explicitly coincide with structural element boundaries; moreover, the cluster boundaries change position from one layer to another. Another drawback of this velocity model is that $V_{0}$ is not allowed to vary laterally such that layer traveltimes, according to the model, are equal to those according to the sonic data at borehole locations.

VELMOD-1 clears away complications and drawbacks of previous seismic velocity models for Netherlands areas. Moreover, the VELMOD-1 database is larger than that of previous velocity models.

\section{Model definition}

VELMOD-1 is defined for nine lithostratigraphic layers (Fig. 1). These layers have been defined by Van Adrichem Boogaert and Kouwe (1993 - 1997); this reference is electronically accessible through www.nlog.nl.

For all layers, except that of the Zechstein Group, the model includes the parameters $V_{0}$ and $\mathrm{K}$ in the linear least squares relation between $V_{\text {int }}$ and $z_{\text {mid }}$ :

$$
\mathrm{V}_{\text {int }}\left(\mathrm{z}_{\text {mid }}\right)=\mathrm{V}_{0}+\mathrm{K} \cdot \mathrm{z}_{\mathrm{mid}}
$$

The $V_{\text {int }}$ and $z_{\text {mid }}$-values stem from non-confidential sonic and deviation data of 720 boreholes in DIN0 - National Geoscientific Portal. The parameters $\mathrm{V}_{0}$ and $\mathrm{K}$ are used as ad hoc parameters in the velocity model:

$$
V(z)=V_{0}+K \cdot z
$$

The parameter $\mathrm{V}_{0}$ is made to vary laterally in two steps. First, $\mathrm{V}_{0}$ is allowed to vary at borehole locations, while $\mathrm{K}$ is kept constant at the value resulting from the above linear least squares relation. Actually, $V_{0}$ is calibrated such that traveltime through the layer according to the velocity model equals the traveltime according to the borehole sonic data. The calibration formula for a borehole at location $(x, y)$ is (Japsen, 1993):

$$
\mathrm{V}_{0}(\mathrm{x}, \mathrm{y})=\mathrm{K} \cdot\left[\mathrm{z}_{\mathrm{b}}-\mathrm{z}_{\mathrm{t}} \cdot \exp (\mathrm{K} \Delta \mathrm{T})\right] \cdot[\exp (\mathrm{K} \Delta \mathrm{T})-1]^{-1}
$$

In the second step, a kriging procedure is applied to the calibrated $\mathrm{V}_{0}$-values resulting in an estimated $\mathrm{V}_{0}$-value at any other location. The $\mathrm{V}_{0}$-values are determined on an areal grid with cells of $1 \mathrm{~km} \times 1 \mathrm{~km}$.

The lithological nature of the Zechstein Group (mainly halite and carbonates) requires a velocity model that is different from the above model. As most rocks of the Zechstein Group are not affected by compaction, a depth-dependent velocity is not 


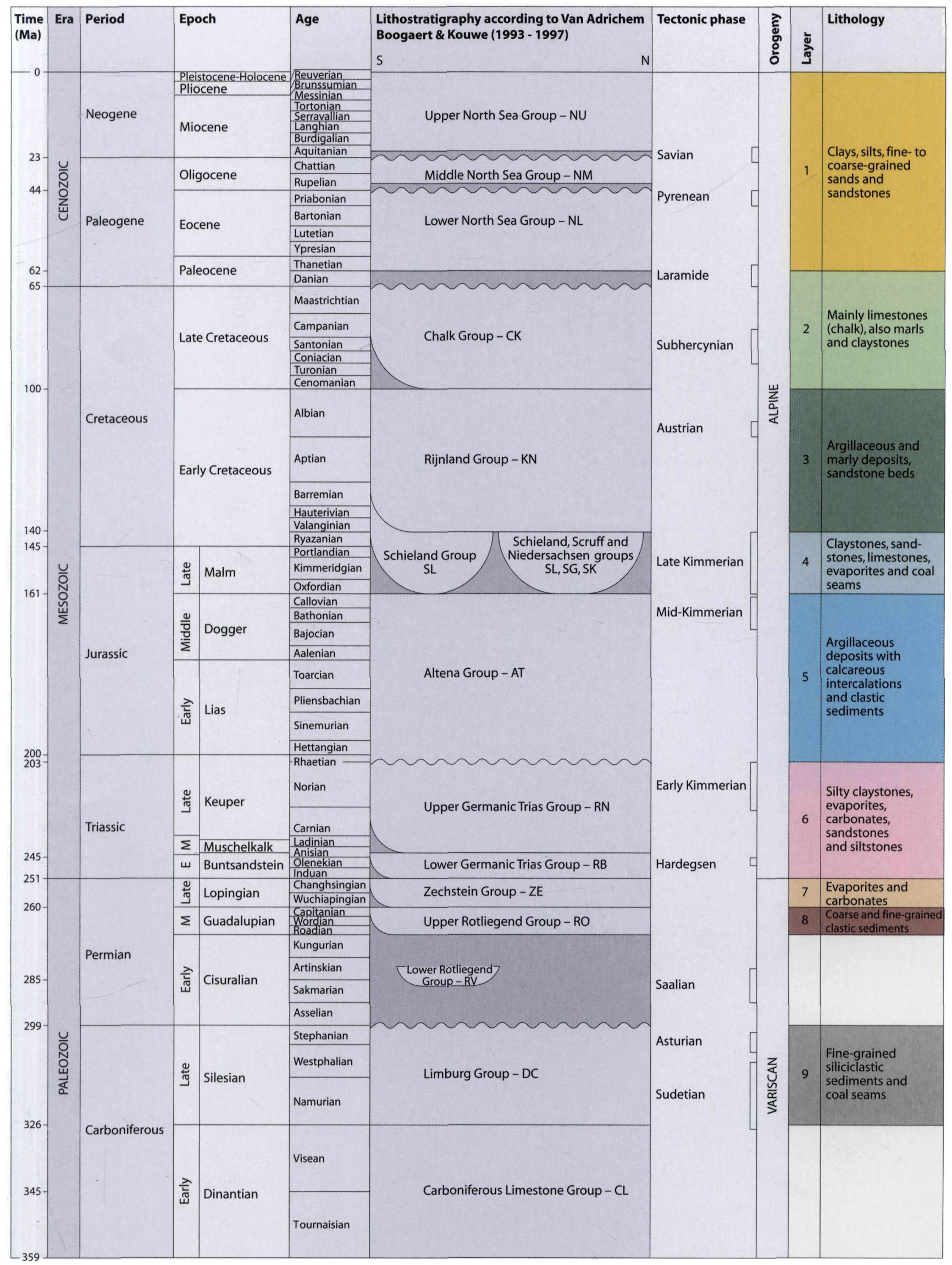

Fig. 1. Geologic time scale (after Gradstein et al. 2004), lithostratigraphic column (after Van Adrichem Boogaert and Kouwe, 1993 - 1997), main tectonic deformation phases and lithostratigraphic layers at the basis of VELMOD-1 with their lithologic characteristics. 


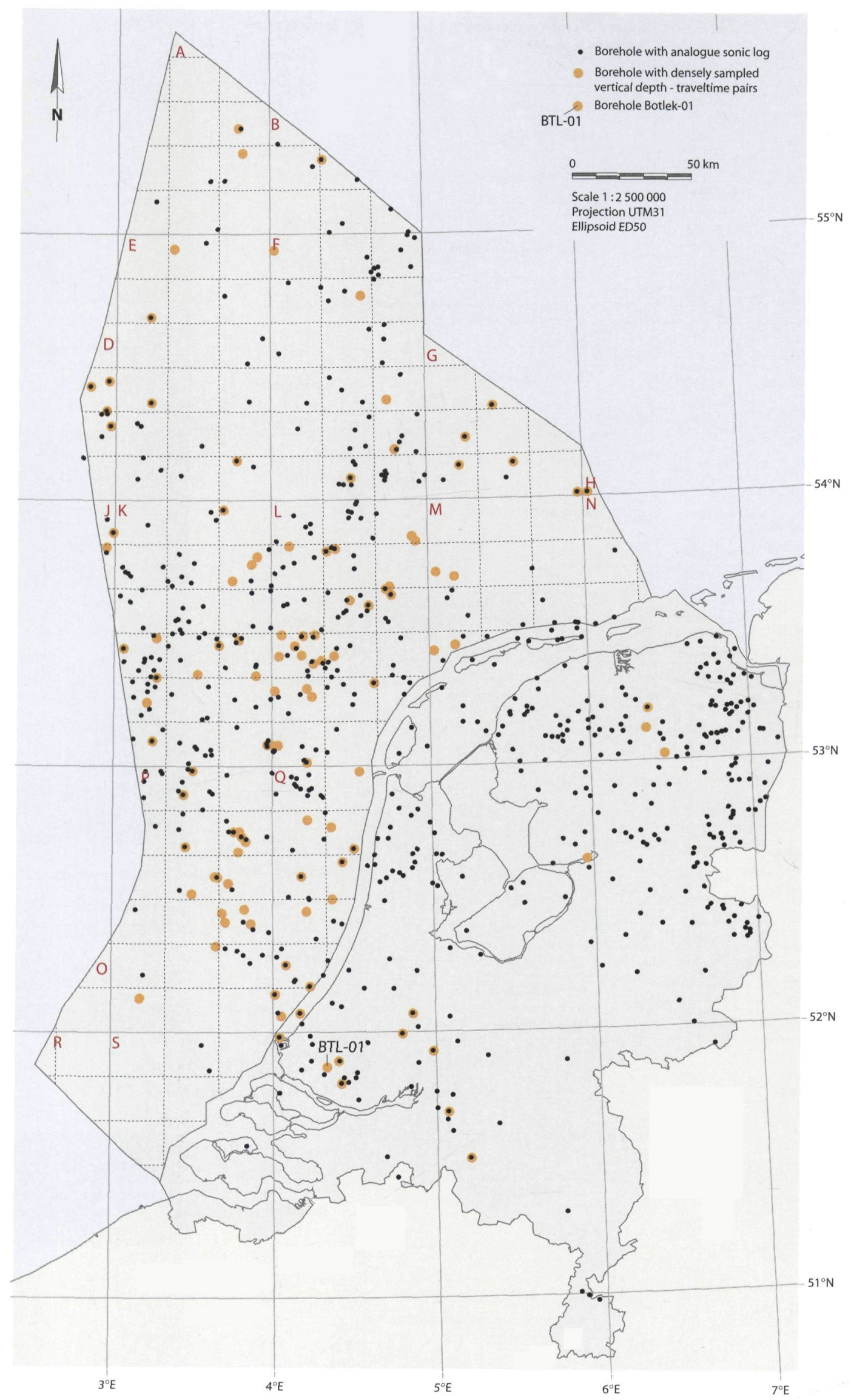

Fig 2. Boreholes with time-depth pairs and/or sonic log data available to VELMOD-1. 
appropriate, and therefore it is sufficient to model with interval velocities. The seismic velocity model for the Zechstein Group is defined in a separate section.

\section{Data and processing}

\section{Analogue sonic logs}

Analogue composite sonic logs were available for 641 boreholes (Fig. 2). The sonic data had been calibrated for 307 of these boreholes. Also available were TNO interpreted depths for top and base of the various lithostratigraphic layers at the borehole locations. From the analogue sonic logs traveltime was read of the acoustic wave traversing a lithostratigraphic layer along the borehole trajectory. Borehole deviation data served to determine the vertical traveltime $\Delta \mathrm{T}$ and the position coordinates of the layer mid-depth $z_{\text {mid }}$, to which was assigned an interval velocity $\mathrm{V}_{\text {int }}=\Delta \mathrm{z} / \Delta \mathrm{T}$ (Fig. 3). As indicated in this figure, $\mathrm{V}_{\text {int }}$ refers to layers that were fully perforated by a borehole. This holds for all layers, except the Limburg Group. For this layer $V_{\text {int }}$ generally represents a part of the complete layer.

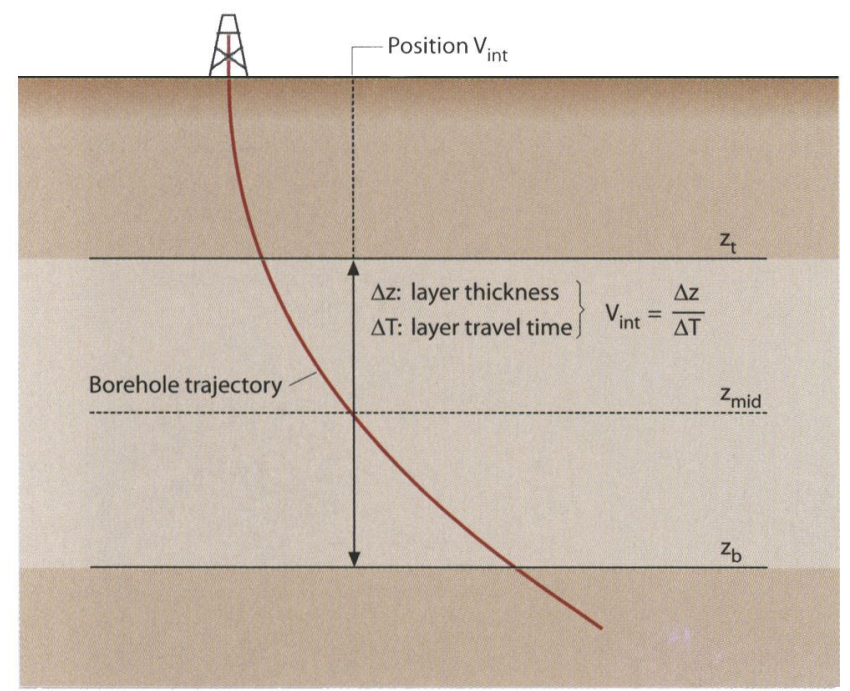

Fig. 3. $V_{\text {int }}$ and its position in case of a layer perforated by a deviated borehole.

\section{Densely sampled time-depth pairs}

For 120 boreholes densely sampled vertical depth-traveltime pairs were available. These boreholes are also shown in Figure 2; it is noted that 41 boreholes with time-depth pairs are included in the set of boreholes with an analogue sonic log. $V_{\text {int }}$-values were determined from the vertical depth-traveltime data and assigned to the position of their layer mid-depths. Again, $V_{\text {int }}$ for the Limburg Group generally represents only a part of the complete layer. The vertical depth-traveltime pairs had been obtained from a digital calibrated sonic log. Figure 4 shows this $\log$ (in velocity representation) for borehole Botlek-01, located in the southwestern part of the onshore (Fig. 2).

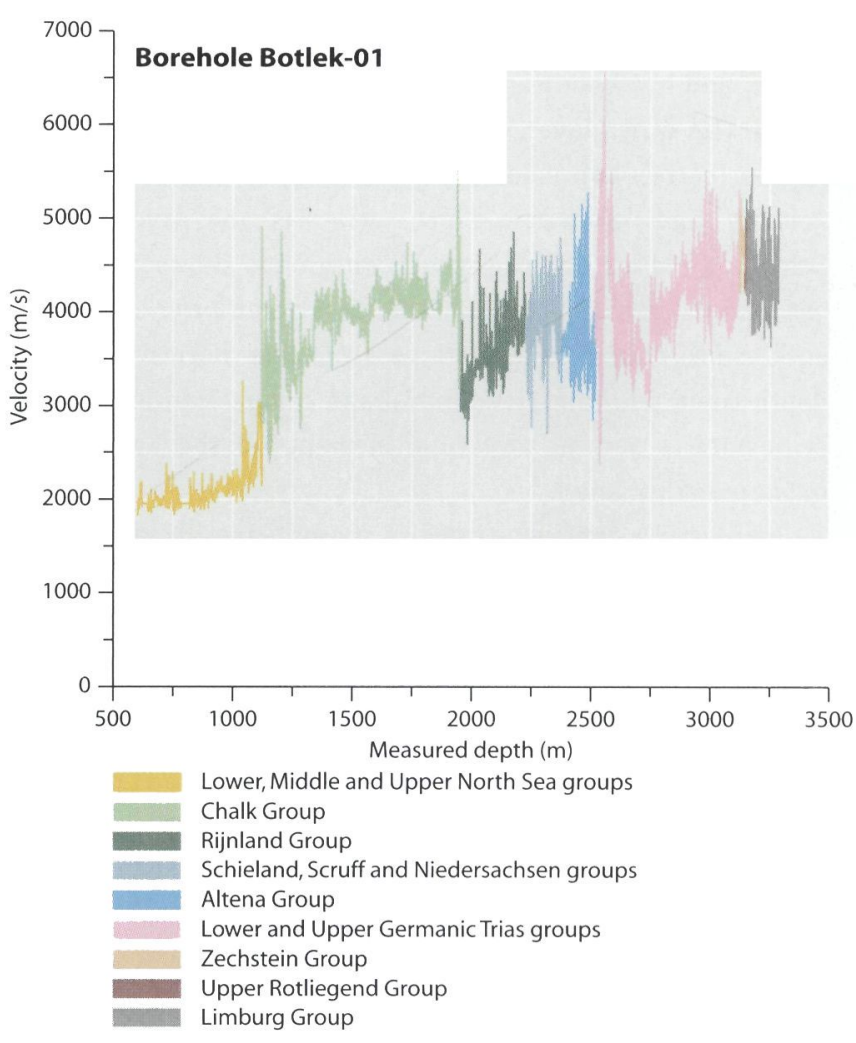

Fig. 4. Velocity representation of sonic log data in borehole Botlek-01 with lithostratigraphic interpretation (see Fig. 2 for location of this borehole).

\section{Quality of the $V_{\text {int }}$ - results}

The quality of the $\mathrm{V}_{\text {int }}$-results is affected by several factors. Layer thickness $\Delta z$ is subject to lithostratigraphic interpretation errors. At a deviated borehole, $\Delta z$ is not accurately calculated in case the layer thickness changes between entry and exit positions of the borehole at respectively top and bottom of the layer. Changes in acoustic properties between entry and exit positions result in an inaccurate vertical traveltime $\Delta \mathrm{T}$. For this reason, $\mathrm{V}_{\text {int }}$-values for vertical boreholes are to be regarded more reliable than those for deviated boreholes.

Furthermore, $V_{\text {int }}$ may be disturbed by inadequacies in sonic logging, elastic anisotropy and dispersion of compressional waves across the frequency range of sonic logging (about $20 \mathrm{kHz}$ ) and exploration seismics (about $20 \mathrm{~Hz}$ ). In this respect, sonic logs calibrated with borehole seismic data are to be preferred above uncalibrated sonic data.

\section{Linear regression results and subdivision into regions based on structural elements}

Linear least squares regression was applied to the interval velocities against mid-depths per lithostratigraphic layer (Fig. 5). It appears that there is no correlation between $V_{\text {int }}$ and $z_{\text {mid }}$ for the layer of the Zechstein Group. This is not surprising as evaporites do not compact. For this reason the 
velocity model for the Zechstein Group is not dependent on depth, and has been based on interval velocities.

For the other layers, that of the Chalk Group shows the highest correlation coefficient $(R=0.833)$ between interval velocity and layer mid-depth, whereas the layer of the Schieland, Scruff and Niedersachsen groups shows the lowest correlation coefficient $(R=0.305)$. The latter lower correlation coefficient points to deviations from the normal velocitydepth trend due to varying burial and compaction histories of sediments in various structural elements of the Netherlands onshore and offshore.

Taking into consideration the present-day distribution of the various lithostratigraphic layers and the tectonic history of the structural elements, a subdivision into two main regions was adopted. Region 1 comprises the areas of the Jurassic basins based on the present-day distribution of Jurassic deposits. Region 2 comprises all areas outside these basins. During the Subhercynian, Laramide and Pyrenean tectonic phases these Jurassic basins were inverted. Due to differences in uplift, these basins were subdivided in three subregions (Fig. 6):

1a. Dutch Central Graben

1b. Broad Fourteens Basin, Central Netherlands Basin, West Netherlands Basin, Roer Valley Graben and Lower Saxony Basin

1c. Terschelling Basin, Vlieland Basin and Step Graben.
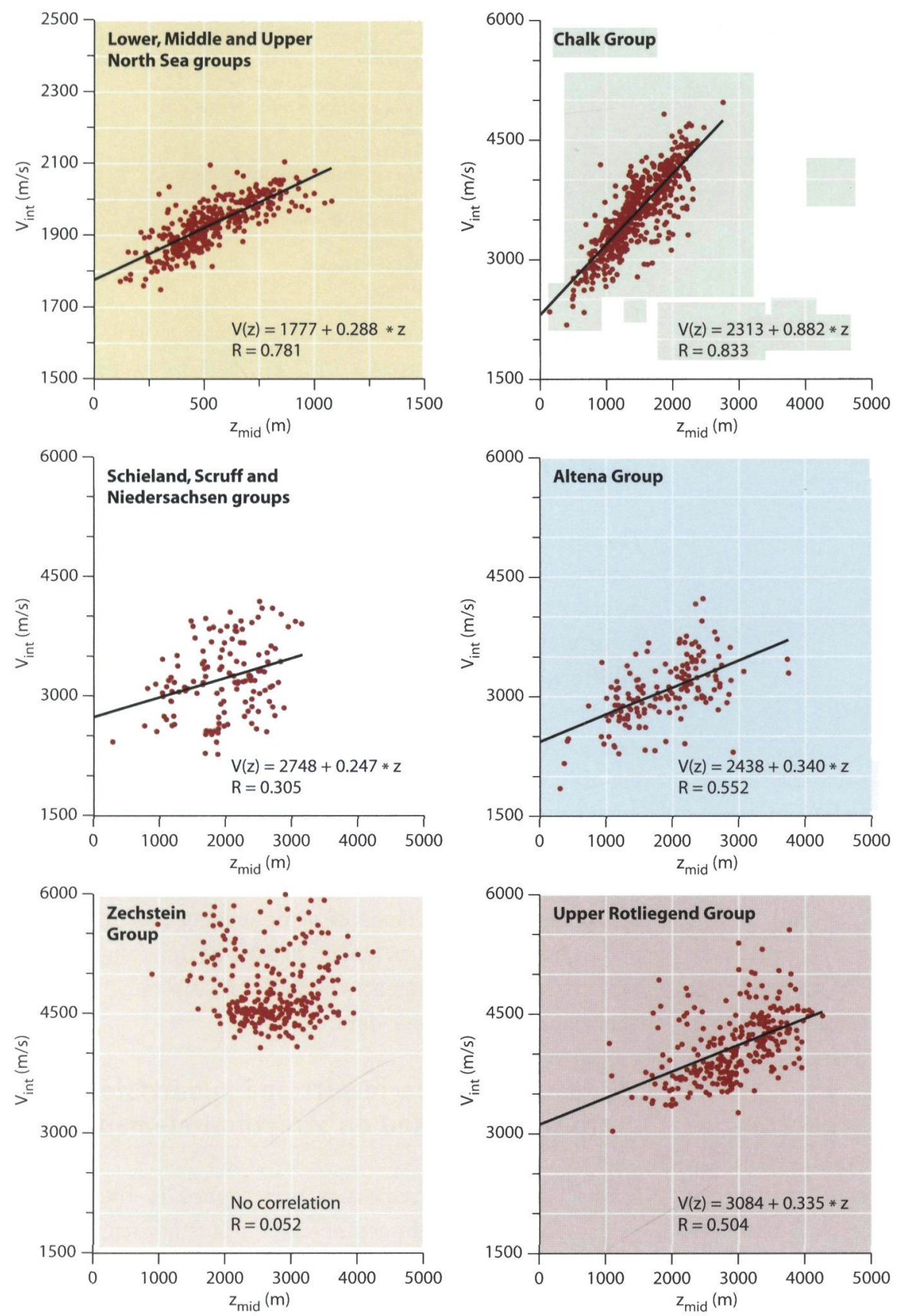
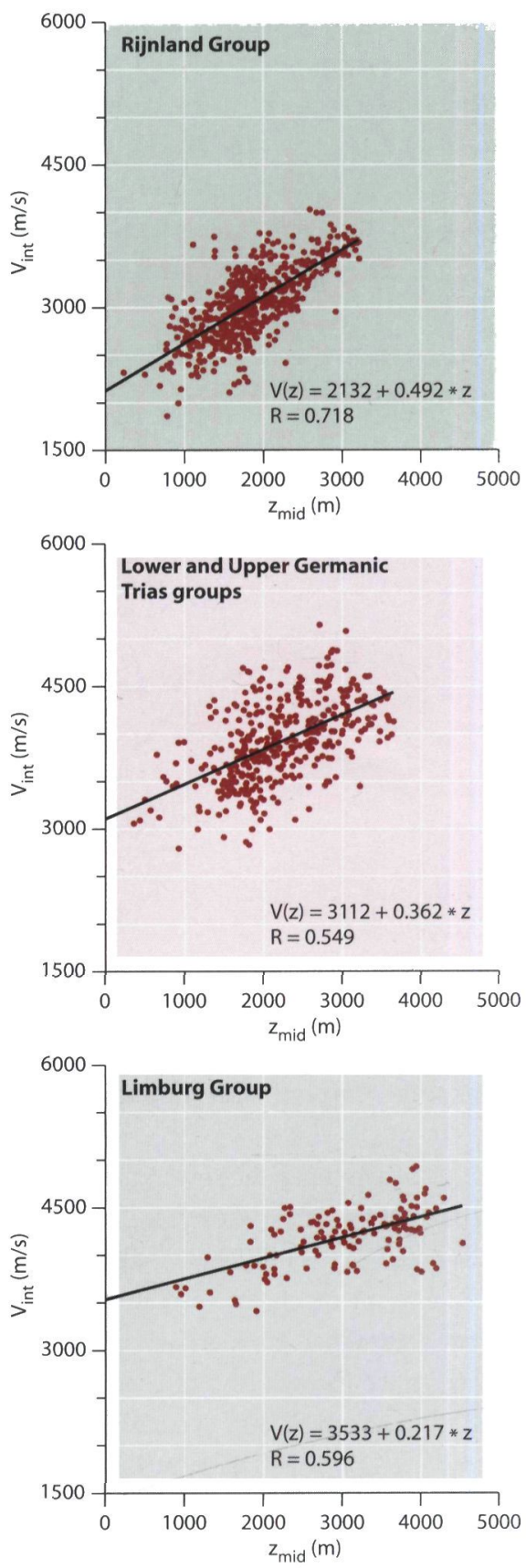

Fig. 5. Linear least squares relation between $V_{\text {int }}$ and $z_{\text {mid }}$ for the various lithostratigraphic layers. 


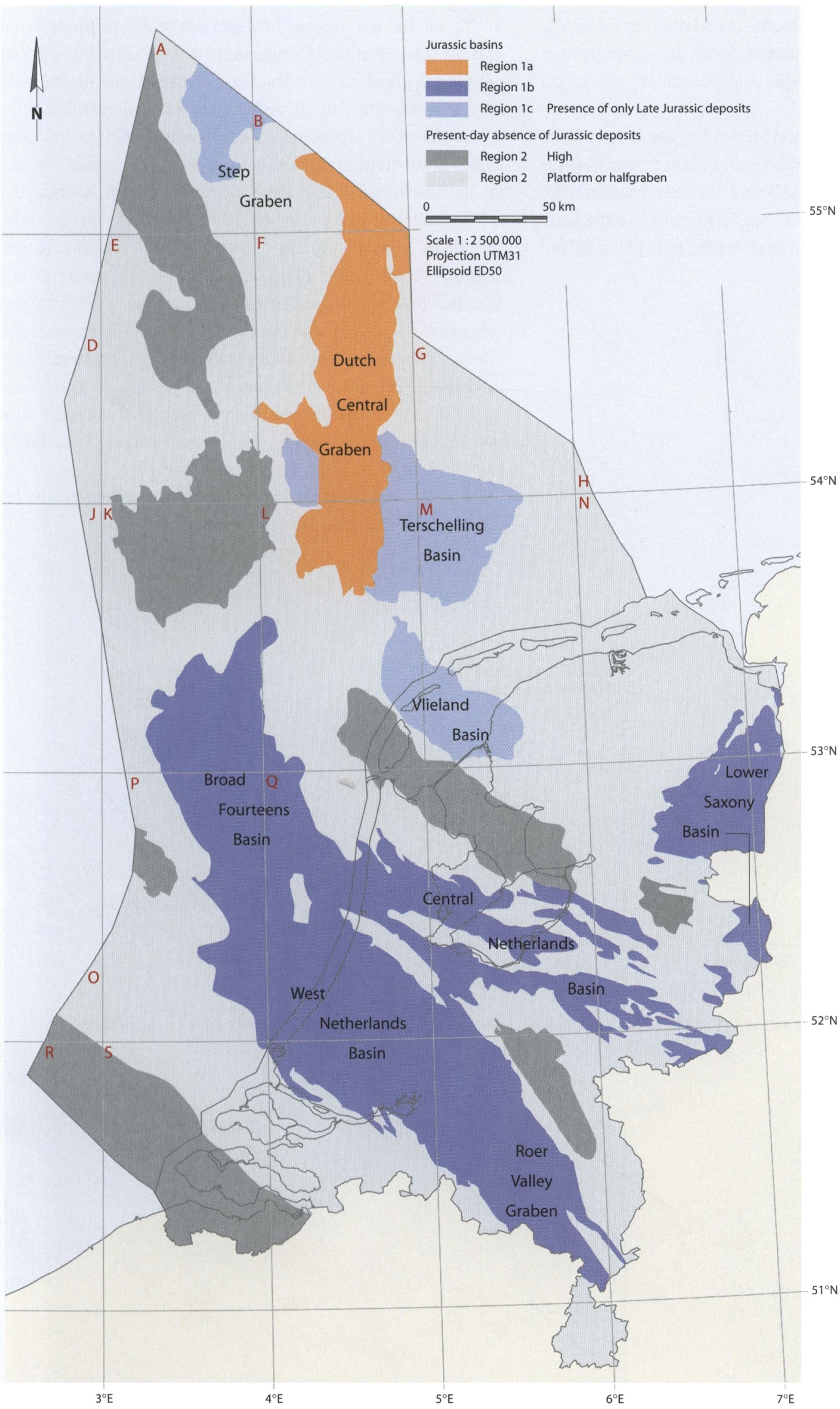

Fig. 6. Subdivision in regions based on the present-day distribution of Jurassic deposits and differences in uplift of the Jurassic basins during Subhercynian, Laramide and Pyrenean tectonic phases. 
Figure 7 shows the linear least squares relations between $V_{\text {int }}$ and $z_{\text {mid }}$ for the layer of the Schieland, Scruff and Niedersachsen groups, both for the above three regions and in case of no subdivision.

Although the correlation coefficient for the layer of the Altena Group ( $R=0.552)$ is considerably higher than that for the layer of the Schieland, Scruff and Niedersachsen groups, the same subdivision into regions has been applied to the layer of the Altena Group. It is noted that region 1c is not involved
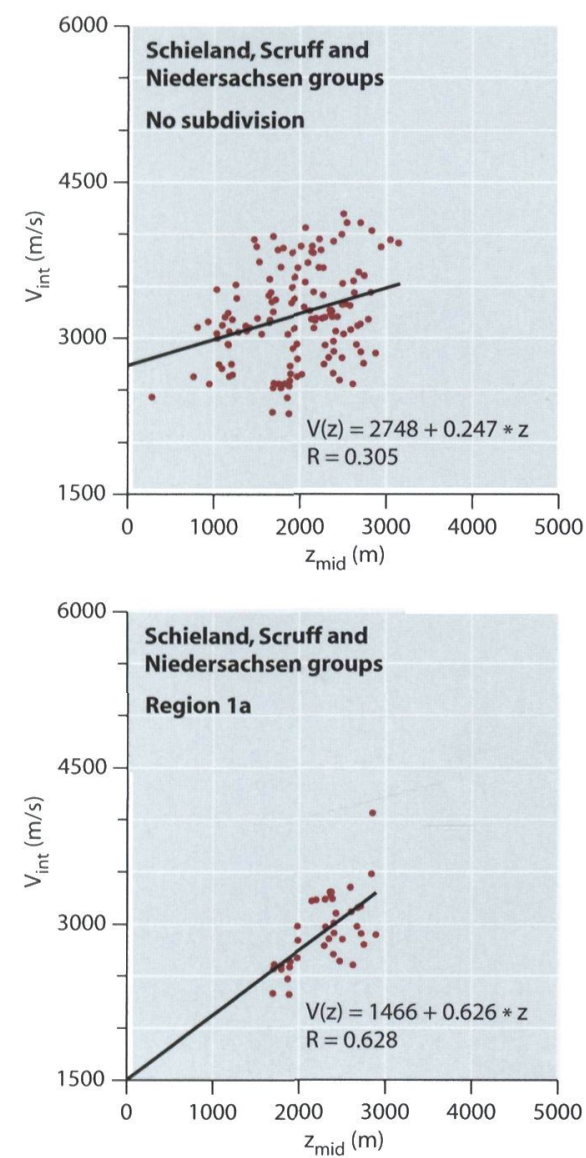

in this subdivision because the layer of the Altena Group is not present there. Figure 8 shows the linear least squares relations between $V_{\text {int }}$ and $z_{\text {mid }}$ for the layer of the Altena Group, both for the regions $1 \mathrm{a}$ and $1 \mathrm{~b}$, and in case of no subdivision.

For the other layers, no subdivision into regions has been made. A subdivision into structural elements is less relevant for the Lower, Middle and Upper North Sea groups, as tectonics is a minor factor in its velocity structure. For the Chalk Group, the main control on the velocity-depth relation is the Cenozoic development (Japsen, 1998). For the layer of the Rijnland Group a vertical subdivision of the layer into two sublayers, one of the Holland Formation and the other of the Vlieland subgroup, seems to be preferable above a subdivision in regions. The same holds for the layer of the Lower and Upper Germanic Trias groups. Here a vertical subdivision into two sublayers is preferable: the Upper Germanic Trias Group and the Lower Germanic Trias Group.

Table 1 summarizes the results of the linear regressions for the K-values of VELMOD-1 per layer and per region.

Fig. 7. Linear least squares relations between $V_{\text {int }}$ and $z_{\text {mid }}$ for the Schieland, Scruff and Niedersachsen groups (without and with subdivision in regions).
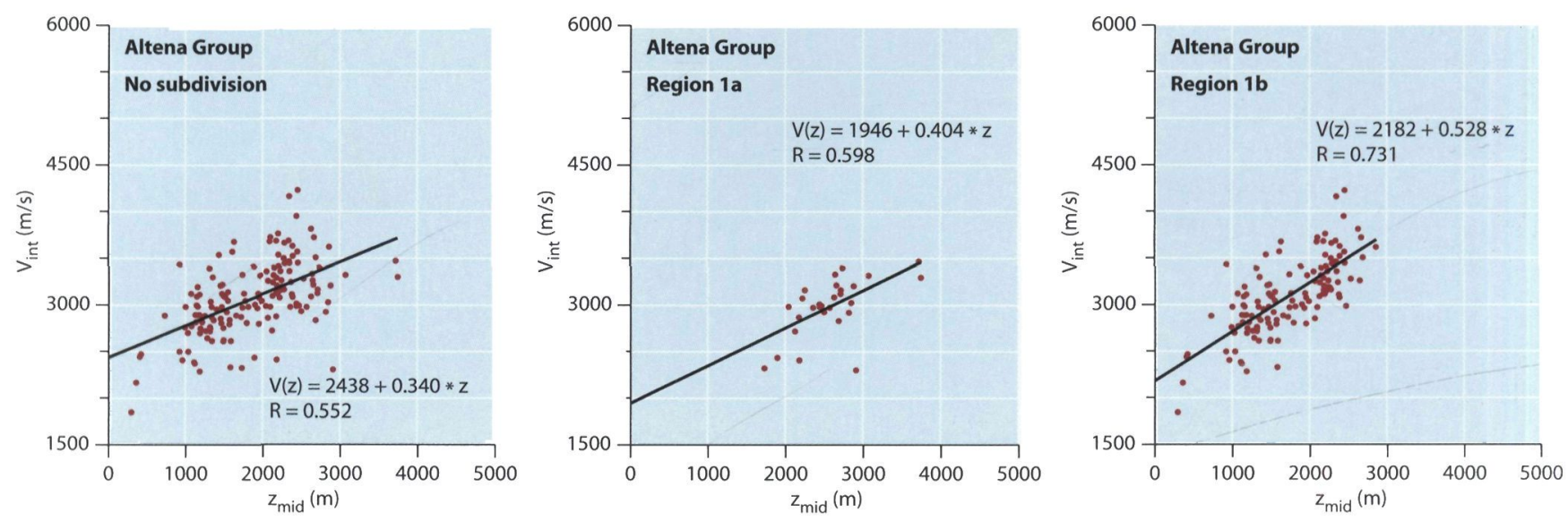

Fig. 8. Linear least squares relations between $V_{i n t}$ and $z_{\text {mid }}$ for the Altena Group (without and with subdivision in regions). 
Table 1. K-values for the lithostratigraphic layers and regions of VELMOD-1.

\begin{tabular}{|c|c|c|c|c|}
\hline Layer & Name & Region & \# boreholes & $K\left(s^{-1}\right)$ \\
\hline 1 & Lower, Middle and Upper North Sea groups & No subdivision & 347 & 0.288 \\
\hline 2 & Chalk Group & No subdivision & 519 & 0.882 \\
\hline 3 & Rijnland Group & No subdivision & 527 & 0.492 \\
\hline 4 & Schieland, Scruff and Niedersachsen groups & Region 1a & 39 & 0.626 \\
\hline 4 & Schieland, Scruff and Niedersachsen groups & Region $1 \mathrm{~b}$ & 69 & 0.658 \\
\hline 4 & Schieland, Scruff and Niedersachsen groups & Region 1c & 26 & 0.959 \\
\hline 5 & Altena Group & Region 1a & 28 & 0.404 \\
\hline 5 & Altena Group & Region 1b & 131 & 0.528 \\
\hline 6 & Lower and Upper Germanic Trias groups & No subdivision & 390 & 0.362 \\
\hline 7 & Zechstein Group & No subdivision & 368 & No correlation \\
\hline 8 & Upper Rotliegend Group & No subdivision & 274 & 0.335 \\
\hline 9 & Limburg Group & No subdivision & 130 & 0.217 \\
\hline
\end{tabular}

The $\mathrm{V}_{0}(\mathrm{x}, \mathrm{y})$-values at the borehole locations $(\mathrm{x}, \mathrm{y})$ are such that they, in combination with the applicable $\mathrm{K}$-value, result in a traveltime $\Delta \mathrm{T}$ equal to the traveltime according to the borehole data. In the next step a kriging procedure is applied to the $\mathrm{V}_{0}(\mathrm{x}, \mathrm{y})$-values at the borehole locations in order to obtain a grid of model $\mathrm{V}_{0}$-values.

\section{Velocity model of the Zechstein Group}

Figure 9 presents seismic traveltime isochores of the Zechstein Group. This map is an interim result of regional seismic mapping projects at TNO. It is used in the construction of the velocity model for the Zechstein Group.

The interval velocity for the Zechstein Group depends mainly on the proportion of halite in the layer, rather than on its depth. Therefore this layer is modelled with interval velocities that are related in a simple way to the relative proportion of halite in the layer.

It is assumed that the interval velocity of the Zechstein Group at locations where its thickness is large, approximates the acoustic velocity of halite (roughly $4500 \mathrm{~m} / \mathrm{s}$ ). At locations where the thickness is relatively small, non-halites may cause deviations from the halite velocity.

Figure 9 is used to model Zechstein layer interval velocities. Where the seismic based two-way traveltime (TWT) is more than $280 \mathrm{~ms}$, the interval velocity is set at $4500 \mathrm{~m} / \mathrm{s}$. Where two-way traveltime is less than $280 \mathrm{~ms}$, interval velocity is a linear function of two-way traveltime:

$$
\begin{aligned}
& V_{\text {int }}=4500 \\
& V_{\text {int }}=5500-3.57 \cdot \text { TWT }
\end{aligned}
$$

for TWT $\geq 280 \mathrm{~ms}$ for TWT $<280 \mathrm{~ms}$

These provisional interval velocities can deviate from the known sonics based interval velocities. Therefore, in the next step, the provisional interval velocities at borehole locations are subtracted from the known sonics based interval velocities.
These differences are interpolated areally and the resulting 'deviation map' is added to the provisional interval velocity map. This result constitutes the final velocity model for the Zechstein Group.

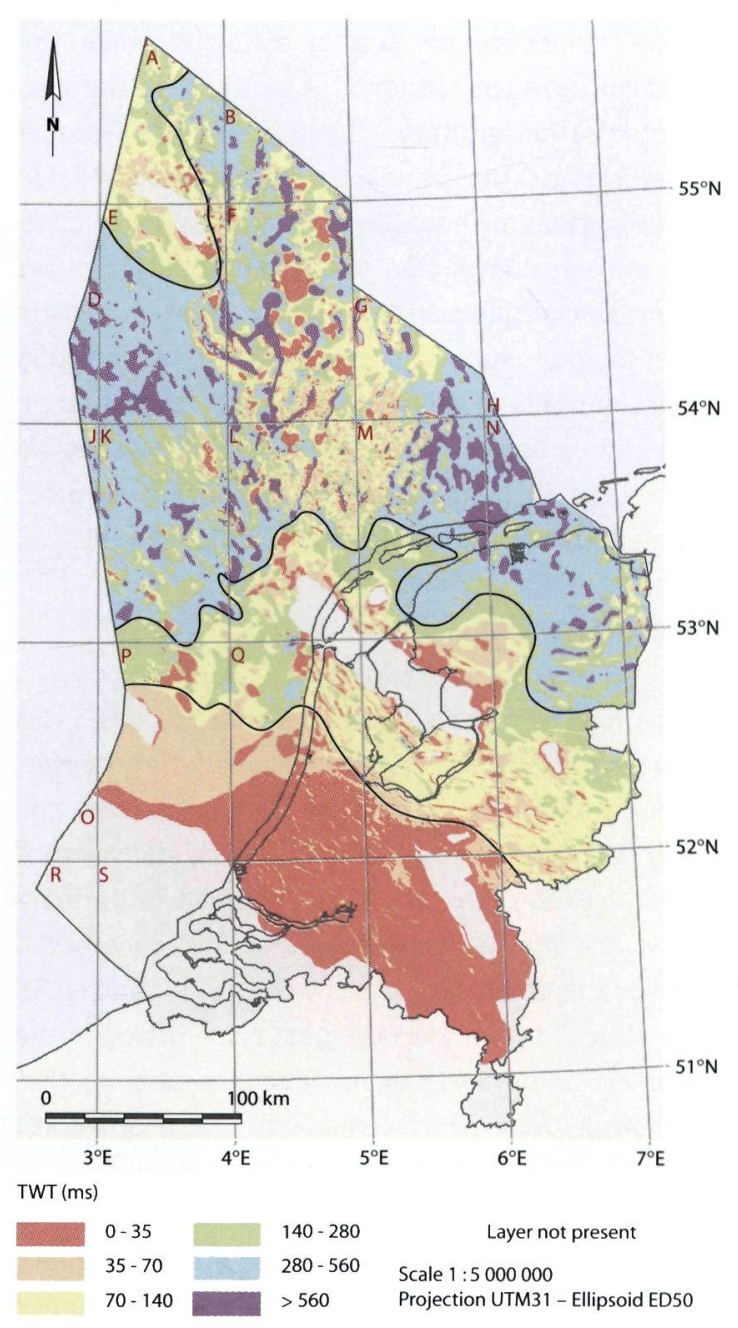

Fig. 9. Preliminary isochores in two-way seismic traveltime (TWT) representation of the layer of the Zechstein Group. 


\section{Geostatistical modelling}

Geostatistics deals with the estimation of attribute values at unvisited locations from surrounding locations where the attribute value is measured. The well known Kriging interpolation methods are taking into account the spatial correlation in the data and preferential clustering of datapoints. With kriging estimation methods the estimated value at a given location is the 'best' estimate in a least-squares fit sense, with the local variance being minimized. The Kriging procedure produces a variance, that is not dependent on local data values, but only on the data configuration and variogram parameters (Goovaerts, 1997).

Simulation methods provide so-called realizations that have the same statistical properties as the input data (histogram and variogram) and honor the data at their location. The smoothing effect, typical for interpolation methods, is not present in realizations and the local variability is correctly presented; for more details regarding simulation techniques, see Goovaerts (1997), Deutsch and Journel (1998).

After generating multiple realizations a mean estimated map and measure of uncertainty can be derived from all realizations. The mean map resembles the Kriging estimate, while the standard deviation, as calculated from the multiple realizations, gives a measure of uncertainty; theoretically, the kriging standard deviation and the standard deviation from a large ensemble of realizations are equal, with a Gaussian distributed variable; it is our experience that the standard deviation, as calculated from the multiple realizations, shows a more realistic representation of the variation compared to the kriging standard deviation; this is probably caused by transforming the original data to a Gaussian distribution and vice versa. We have chosen for the Sequential Gaussian Simulation method, because it is well known and rather simple to implement.

\section{Sequential Gaussian Simulation}

To be able to perform Sequential Gaussian Simulation (SGS) it is necessary to transform all data to Gaussian space. After transformation, a variogram is produced from the transformed data and Simple Kriging (SK) is performed to obtain a mean and variance for a prediction location. The use of SK (in stead of 0rdinary Kriging $0 \mathrm{~K}$ ) is one of the requirements of SGS (Goovaerts, 1997; Deutsch and Journel, 1998). The weights used in the SK procedure are obtained from the variogram model fitted to the data. The mean and variance at the prediction location together form a distribution, from which a value is randomly drawn. This value will be the simulated value for the grid cell.

This value is added to the dataset and will be used as data point when SK is performed to obtain a mean and variance for the next prediction location. This procedure is repeated until all grid cells have been visited. We now have one realization. This realization is transformed back into normal space. The whole procedure is repeated to obtain multiple realizations. Each realization has approximately the same statistical properties (histogram and variogram) as the original data and satisfies the original data at the data locations. From all realizations together a mean and a measure of uncertainty (standard deviation) is derived.

\section{The variogram}

An important tool in the estimation procedure is the variogram. The variogram is a so-called 'two-point' statistical measure, showing the average squared difference for pairs of points separated by a certain distance. As the distance increases, the average difference will normally increase, until a certain distance at which the average difference is leveling off. At this distance, called the range, there is no spatial correlation between the data points anymore. The nugget is the spatial variation occurring at very small distances, together with the spatial uncorrelated measurements error. The sill is the variance that occurs at the distance where there is no spatial correlation anymore. At the range, the sill is about the variance of the dataset, which equals 1.0 in the case of Gaussian transformed variables.

The experimental variogram gives, at a specified distance interval, the average of the squared variance of the variable that is studied. To use the variogram in estimation, a variogram model is fitted through the experimental variogram. Not every model is allowed to represent the experimental variogram, only so called positive-definite models. For more detail see Goovaerts (1997) and Deutsch and Journel (1998).

In the variogram modelling we choose to set the nugget value to 0 , thereby implying that the short distance correlation and the measurements error ('noise') are less important in our regional study. Furthermore, we have decided to use isotropic variograms, since these gave better results that anisotropic variograms.

\section{Variogram modelling}

The Simple Kriging algorithm in the Sequential Gaussian procedure uses a variogram model to determine the weights for the data points within the search radius. For each layer a variogram model is fitted to the experimental variogram of the (to Gaussian space transformed) data belonging to each region, or to the whole dataset when no subdivision into regions is used for that specific layer. For all models the sill is set to 1 , which is, per definition, the variance of the Gaussian dataset, and the nugget to 0 . A non-zero nugget indicates that repeated measurements at the same point yield different values. By choosing a zero nugget, we disregard errors in the $V_{\text {int }}$ data. Figure 10 and 11 show the variogram of the Chalk Group and the Lower and Upper Germanic Trias groups, respectively. 


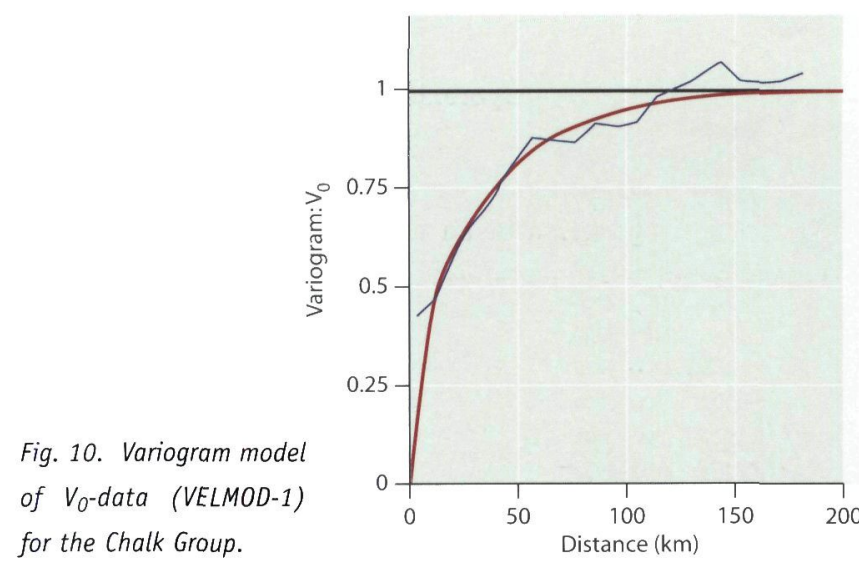

Fig. 11. Variogram model of $V_{0}$-data (VELMOD-1) for the Lower and Upper Germanic Trias groups.

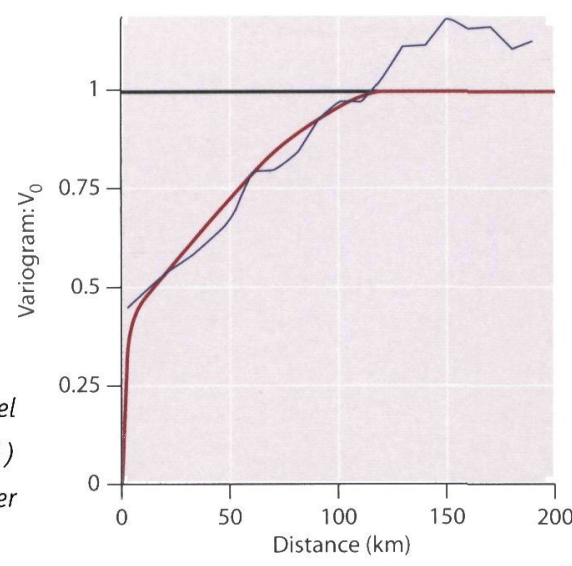

\section{$V_{0}$ modelling}

Within the Sequential Gaussian Simulation 50 realizations of the $\mathrm{V}_{0}$ distribution have been generated for the various layers and regions. The final $V_{0}$ distribution map is the mean of these 50 realizations, its corresponding measure of uncertainty is a map representing the standard deviation of the 50 realizations. For layers that have been subdivided into regions, the realizations have been generated per region, after which the resulting mean and standard deviation of the different regions have been merged into one final $\mathrm{V}_{0}$-distribution map and one uncertainty map for the whole area.

\section{Results and discussion}

The K-values of Table 1 together with the $1 \mathrm{~km} \mathrm{x} 1 \mathrm{~km}$ grids of the kriged $V_{0}(x, y)$-values determine the parameter values of the linear functions $\mathrm{V}(\mathrm{x}, \mathrm{y}, \mathrm{z})=\mathrm{V}_{0}(\mathrm{x}, \mathrm{y})+\mathrm{K}(\mathrm{x}, \mathrm{y}) \cdot \mathrm{z}$ in VELMOD-1. These functions have been determined for all lithostratigraphic layers of Fig. 1, except that of the Zechstein Group. For the latter layer VELMOD-1 consists of a $1 \mathrm{~km} \times 1$ $\mathrm{km}$ grid of kriged interval velocities, based on borehole data and seismic traveltimes according to Fig. 9. To all grids of kriged velocities is attached a grid of standard deviations. The complete model will be accessible to the public as of March 1, 2008 (www.nlog.nl).
Figure 12 shows a map of the VELMOD- $1 \mathrm{~V}_{0}$-distribution of the Chalk Group. The standard deviation of this distribution is shown in Figure 13. Similarly, Figures 14 and 15 show the VELMOD-1 distributions of $\mathrm{V}_{0}$ and its standard deviation for the Lower and Upper Germanic Trias groups.

The $\mathrm{V}_{0}$-values of the Chalk Group range from less than $1500 \mathrm{~m} / \mathrm{s}$ to $2900 \mathrm{~m} / \mathrm{s}$, at a constant $\mathrm{K}$-value of $0.882 \mathrm{~s}^{-1}$. A large area of low $(<2000 \mathrm{~m} / \mathrm{s}) \mathrm{V}_{0}$-values occurs in the northern part of the offshore area. This feature of the velocity model is thought to be attributable to undercompaction of sediments of the Chalk Group due to pore fluid overpressure here (Simmelink et al., 2005). Undercompaction of sediments of the Chalk Group implies that the constant $\mathrm{K}$-value of $0.882 \mathrm{~s}^{-1}$ is larger than the actual $\mathrm{k}$-values. Consequently, $\mathrm{V}_{0}$-values tend to be low.

An area of high $(2700-2900 \mathrm{~m} / \mathrm{s}) \mathrm{V}_{0}$-values occurs within the K-quadrant of the offshore area. Here, the Chalk Group attains great depths and large thicknesses (Duin et al., 2006). These high $\mathrm{V}_{0}$-values are attributed to a relatively strong increase of instantaneous velocity $\mathrm{v}$ with depth $\mathrm{z}$ at greater depths for sediments of the Chalk Group (Japsen, 2000). This phenomenon implies that the constant $\mathrm{K}$-value of $0.882 \mathrm{~s}^{-1}$ is smaller than the actual $\mathrm{k}$-values. Consequently, $\mathrm{V}_{0}$-values tend to be high.

The $\mathrm{V}_{0}$-values of the Lower and Upper Germanic Trias groups range from less than $2400 \mathrm{~m} / \mathrm{s}$ to $4200 \mathrm{~m} / \mathrm{s}$, at a constant $\mathrm{K}$-value of $0.362 \mathrm{~s}^{-1}$. Low $\mathrm{V}_{0}$-values $(2400-2800 \mathrm{~m} / \mathrm{s})$ occur mostly in the offshore area, whereas high $\mathrm{V}_{0}$-values $(3400-3800 \mathrm{~m} / \mathrm{s})$ occur in a large area covering the Roer Valley Graben, the Central Netherlands Basin, the West Netherlands Basin and the Broad Fourteens Basin. As yet, the causes of these differences in $\mathrm{V}_{0}$-values are not clear. 


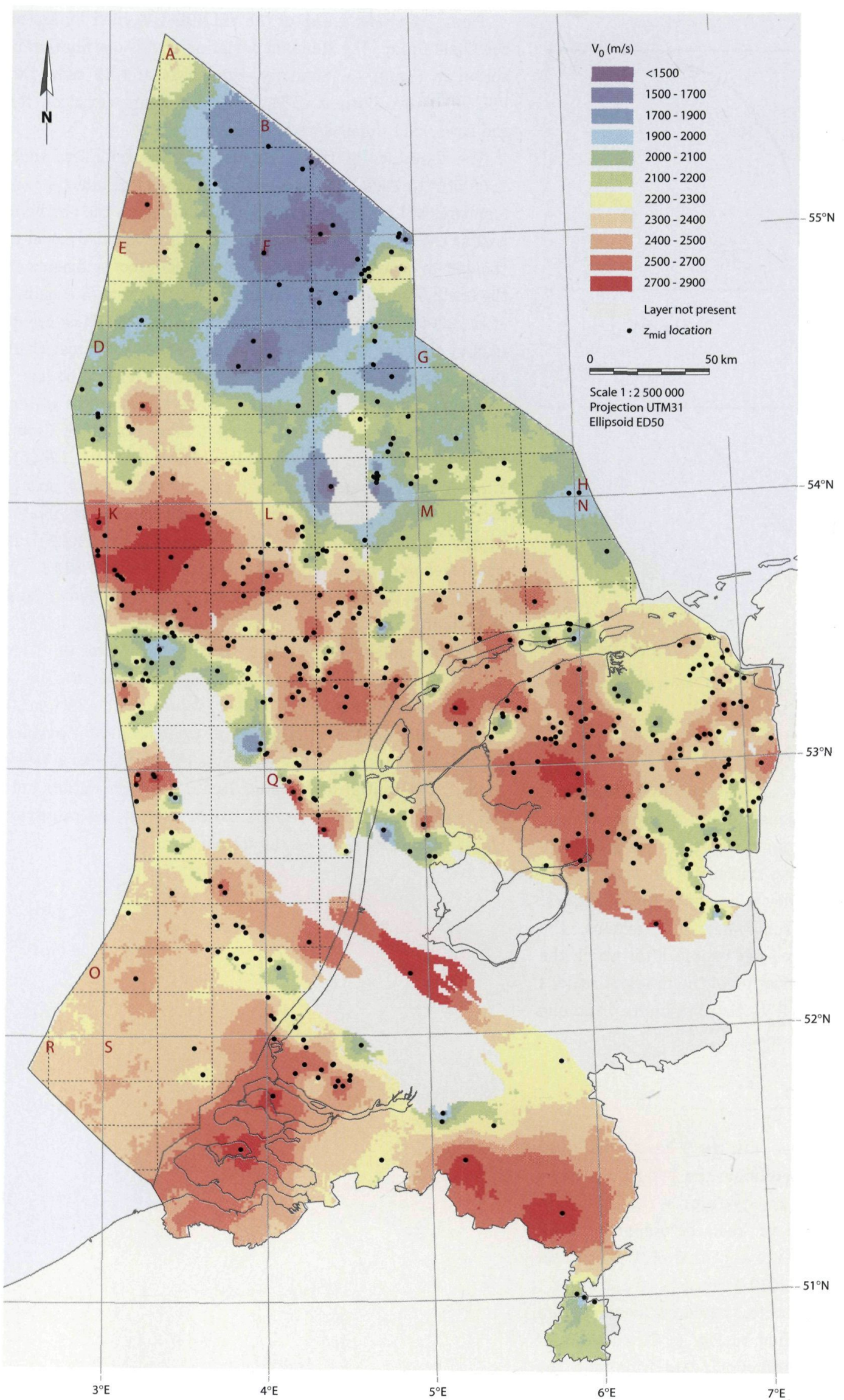

Fig. 12. V-distribution (VELMOD-1) across the layer of the Chalk Group. 


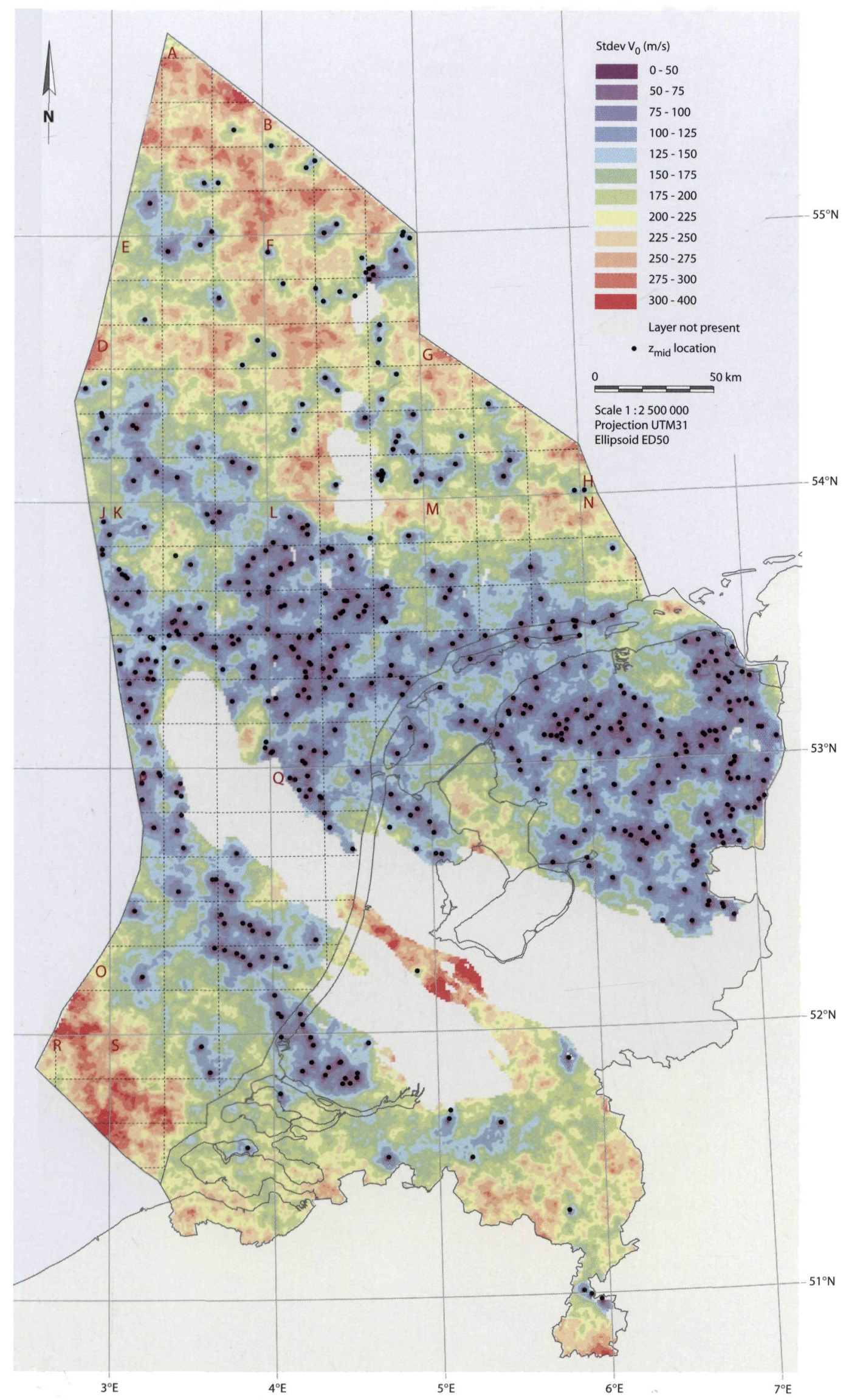

Fig. 13. Standard deviation of $V_{0}$ (VELMOD-1) across the layer of the Chalk Group. 


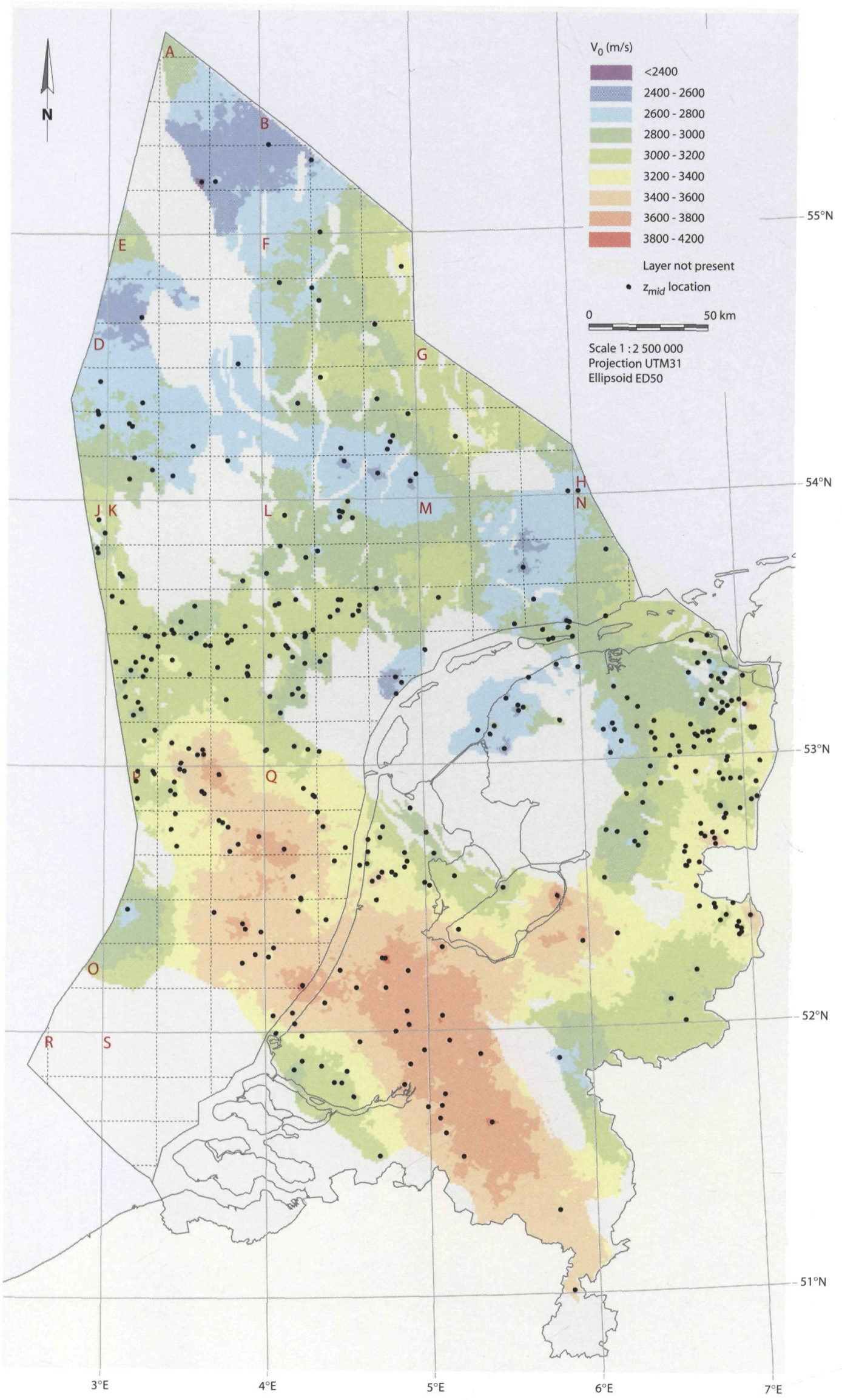

Fig. 14. V-distribution (VELMOD-1) across the layer of the Lower and Upper Germanic Trias groups. 


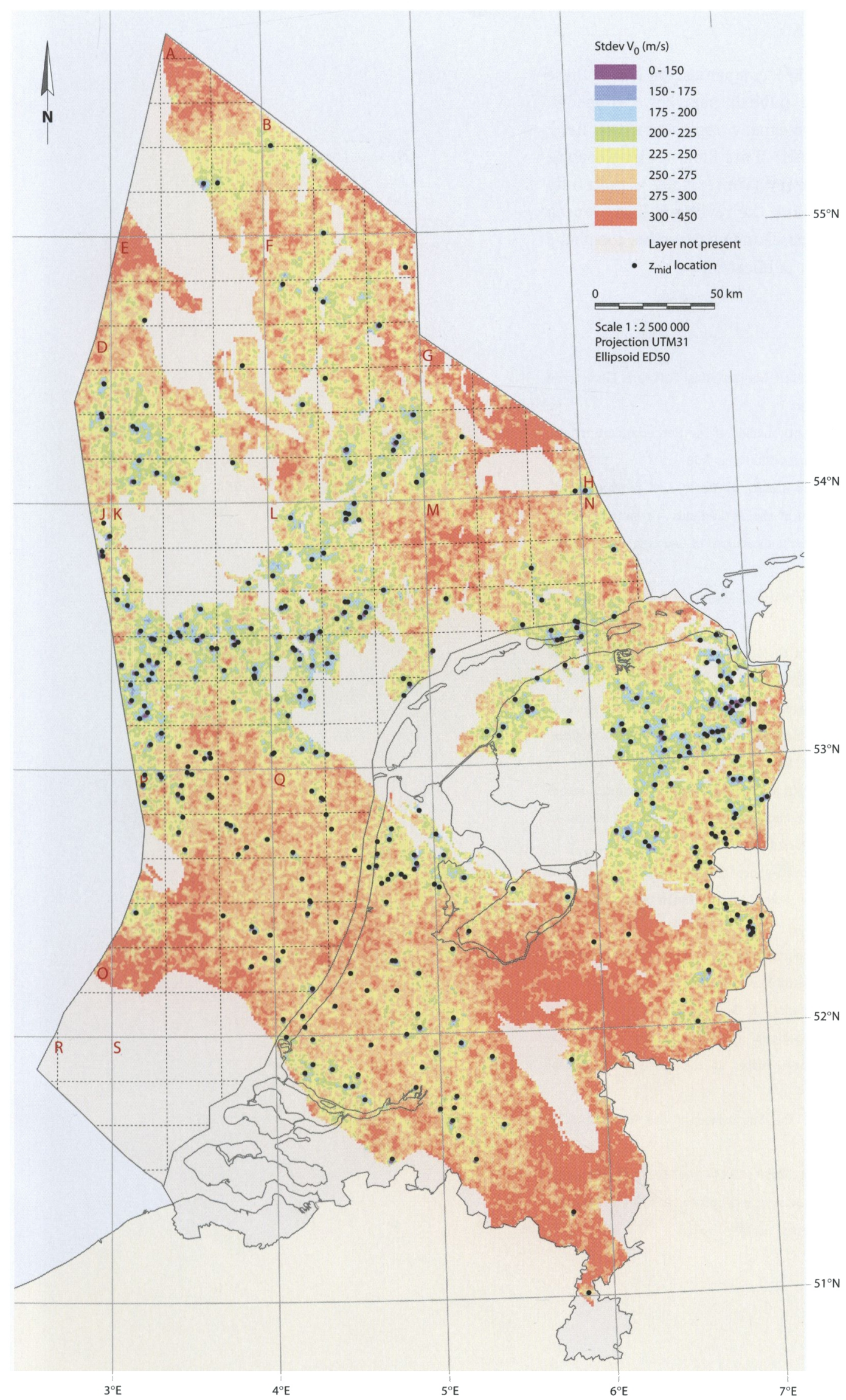

Fig. 15. Standard deviation of $V_{0}$ (VELMOD-1) across the layer of the Lower and Upper Germanic Trias groups. 


\section{Acknowledgements}

VELMOD-1 was funded by five E\&P companies. We thank these companies for permission to publish parts of the model. Constructive support of the company representatives Henk Koster (EBN), Guido Hoetz (NAM), Frits Blom (Petro-Canada), Bob Bins (Total) and Fiona Dewey (Wintershall) is gratefully acknowledged. The authors thank the reviewers Peter Japsen and Olivier Dubrule for their critical and constructive comments on the first manuscript of this publication.

\section{References}

Deutsch, C.V. \& Journel, A.G., 1998. GSLIB, Geostatistical Software, Library and User's Guide, Oxford University Press.

Doornenbal, J.C., 2001. Regional velocity models of the Netherlands territory. 63rd EAGE Conference Expanded Abstracts, Paper A08.

Duin, E.J.T., Doornenbal, J.C., Rijkers R.H.B., Verbeek, J.W. \& Wong, Th.E. (this volume). Subsurface structure of the Netherlands - results of recent onshore and offshore mapping. Netherlands Journal of Geosciences / Geologie en Mijnbouw 85-4: 245-276.

Goovaerts, P., 1997. Geostatistics for Natural Resources Evaluation, Oxford University Press: $496 \mathrm{pp}$.

Gradstein, F.M., Ogg, J.G. \& Smith, A.G. (eds), 2004. A geologic time scale 2004. Cambridge University Press: 589 pp.

Japsen, $P_{.}, 1993$. Influence of lithology and Neogene uplift on seismic velocities in Denmark: implications for depth conversion of maps. American Association of Petroleum Geologists Bulletin 77, No. 2: 194-211.

Japsen, P., 1998. Regional velocity-depth anomalies, North Sea Chalk: a record of overpressure and Neogene uplift and erosion. American Association of Petroleum Geologists Bulletin 82, No. 11: 2031-2074.

Japsen, P., 2000. Investigation of multi-phase erosion using reconstructed shale trends based on sonic data. Sole Pit axis, North Sea. Global and Planetary Change 24: 189-210.

Robein, E., 2003. Velocities, Time-imaging and Depth-imaging in Reflection Seismics. Principles and Methods, EAGE Publications b.v.

Simmelink, E., Verweij, H., Underschultz, J. \& Otto, C.J., 2005. A quality controlled pressure database and a regional hydrodynamic and overpressure assessment in the Dutch North Sea. Poster at the AAPG 2005 Annual Convention.

TNO-NITG，2004. Geological Atlas of the Subsurface of the Netherlands onshore: $103 \mathrm{pp}$.

Van Adrichem Boogaert, H.A. \& Kouwe, W.F.P., 1993 - 1997 (eds). Stratigraphic nomenclature of the Netherlands, revision and update by RGD and NOGEPA, Mededelingen Rijks Geologische Dienst, nr. 50. 